\title{
Irradiation of Diamond-like Carbon Films by Picosecond Laser Pulses
}

\author{
Liutauras MARCINAUSKAS ${ }^{* 1}$, Alfonsas GRIGONIS ${ }^{* 1}$, Mindaugas GEDVILAS ${ }^{* 2}$, Lina VIGRICAITE ${ }^{* 1}$, Gediminas \\ RAČIUKAITIS $^{* 2}$, Živilè RUTKŪNIENË ${ }^{* 1}$, and Marius ČERNAUSKAS ${ }^{* 1}$ \\ ${ }^{* 1}$ Kaunas University of Technology, Studentu str. 50, LT-44029 Kaunas, Lithuania \\ E-mail: liutauras.marcinauskas@ktu.lt \\ ${ }^{* 2}$ Center for Physical Sciences and Technology, Savanoriu Ave. 231, LT-02300 Vilnius, Lithuania
}

\begin{abstract}
The picosecond laser irradiation of diamond-like carbon (DLC) film on the silicon was investigated. The DLC films were irradiated by Nd: $\mathrm{YVO}_{4}$ laser with the infrared $\left(1064 \mathrm{~nm}\right.$, fluency $1.02 \mathrm{~J} / \mathrm{cm}^{2}$ ) and ultraviolet $\left(355 \mathrm{~nm}\right.$, fluency $0.79 \mathrm{~J} / \mathrm{cm}^{2}$ ) wavelengths with 1,10 , and 100 pulse numbers per spot. The energy dispersive X-ray spectroscopy and microRaman spectroscopy measurements indicated that the full ablation area of the DLC was narrower than laser beam radius of the $1064 \mathrm{~nm}$ wavelength with 10 and 100 pulses. The increase of the oxygen concentration was obtained near the ablation areas after irradiation with the first harmonic. The microRaman and SEM measurements demonstrated that the DLC film was fully ablated in the laser spot when the third harmonic was used. The formation of silicon carbide $(\mathrm{SiC})$ in the center of the irradiated spot was found after 100 pulses.
\end{abstract}

DOI: $10.2961 / \mathrm{jlmn} .2015 .01 .0009$

Keywords: Picosecond laser irradiation, diamond-like carbon, laser ablation, graphitization

\section{Introduction}

The surface modification of solids by various laser pulses has been studied for a wide range of materials [1-3]. Nowadays surface modification studies of the thin film semiconductors, especially amorphous carbon films by various types of energetic beams, including laser beam are of great technological and fundamental interest [4-10].

The unique physical, mechanical, optical, and electrical properties of amorphous carbon films, such as diamondlike carbon (DLC) or tetrahedral amorphous carbon (ta-C) are attractive for applications in microelectronincs, sensor technologies, solar photonic, tribological and biomedical fields [10-12]. It was demonstrated that it is possible to create periodical structures or ripple patterns not only on target surfaces of various materials, but even on surfaces with various semiconductors films such as DLC, $\mathrm{SiC}, \mathrm{GaN}$, and etc [4, 7-9]. Recent researches showed that DLC periodic structures have potential applications in lithography or high density data storage [7].

Lasers induced processes in amorphous carbon films, especially on the surface are influenced by the film material properties $\left(\mathrm{sp}^{2}\right.$ and $\mathrm{sp}^{3}$ sites fraction, hydrogen concentration) and laser parameters (wavelength, pulse duration, number of pulses, repetition rate etc.) [12-19]. Y. Dong et al. [13] reported that the ablation threshold of DLC films decreases with increasing number of pulses. T. Roch et al. $[9,14]$ demonstrated that the direct laser interference patterning of ta-C films reduce the coefficient of friction up to $\sim 30 \%$. N.T. Panagiotopoulas et al. [6] observed the formation of $\mathrm{SiC}$ at the $\mathrm{a}-\mathrm{C}: \mathrm{H}$ film/Si interface and film graphitization, when 35 ps laser irradiation with the 1064 $\mathrm{nm}$ and $266 \mathrm{~nm}$, respectively, was used. P. Patsalas [12] managed to vary the structural features and optical properties (refractive index) of a-C:H by picosecond laser radiation. G.Miyaji et al. [7, 16] demonstrated the nanostructure formation on the DLC surface irradiated at low fluence of femtosecond laser pulses.
The ablation and modification of the DLC films by the nanosecond laser pulses are stipulated by the thermal processes and are already well widely investigated. Meanwhile the 2D and 3D nanostructuring of the surfaces with picosecond laser pulses is attractive and promising tool. Although the physical and thermal processes induced in the DLC films by ps laser pulses are not understood yet and well explained. So far no satisfactory researches have been made investigating the picosecond laser pulses effect on the DLC films.

To investigate the influence of the picosecond laser beam wavelength and pulse number on the surface morphology and structure of the DLC films were the main purpose of the work was.

\section{Experimental setup}

The diamond-like carbon (DLC) film was deposited on the silicon substrate by radio frequency chemical vapour deposition technique using acetylene gas. The thickness of the DLC film was $\sim 300 \mathrm{~nm}$, the refractive index was 2.03, hardness was $\sim 25 \mathrm{GPa}$, Young's modulus - $190 \mathrm{GPa}$. The DLC film was irradiated with a picosecond $\mathrm{Nd}: \mathrm{YVO}_{4}$ laser (Ekspla PL10100) using the first $(1064 \mathrm{~nm})$ and the third (355 nm), harmonics. The irradiation was performed using the $1.02 \mathrm{~J} / \mathrm{cm}^{2}$ and $0.79 \mathrm{~J} / \mathrm{cm}^{2}$ fluency for the first and the third harmonics, respectively. The pulse duration was 10 picoseconds, while the repetition rate was $100 \mathrm{kHz}$. The radius ( $\mathrm{r}$ ) of the laser beam spots, measured at $1 / \mathrm{e}^{2}$ level were $30 \mu \mathrm{m}$ and $15 \mu \mathrm{m}$ for the first and the third harmonics, respectively. The pulse number was 1,10 , and 100 per spot The films surface morphology was investigated by scanning electron microscope (SEM) JEOL JSM6490LV. The irradiated films were analyzed using microRaman spectroscopy (Renishaw inVia spectrometer, $633 \mathrm{~nm}, 100 \mathrm{~s}, 1 \mathrm{~mW}$, spot size $2 \mu \mathrm{m})$. The energy dispersive X-ray spectroscopy (EDS) (Bruker Quad 5040 spectrometer) was used for the measurement of elemental composition. 


\section{Results and discussions}

The spectrum of the non-irradiated DLC indicates a D $\left(1274 \mathrm{~cm}^{-1}\right)$ and $\mathrm{G}\left(1499 \mathrm{~cm}^{-1}\right)$ peaks (Fig. 1). The full width at half-maxima (FWHM) of the D band $(\Delta \mathrm{D})$ was $217 \mathrm{~cm}^{-1}$, while FWHM of the $\mathrm{G}$ band $(\Delta \mathrm{G})$ was $174 \mathrm{~cm}^{-1}$. The integral intensity $I_{D} / I_{G}$ ratio was 0.53 . Such $I_{D} / I_{G}$ ratio is typical for the DLC films, indicating that the $\mathrm{sp}^{3} \mathrm{C}-\mathrm{C}$ sites fraction are dominating among the $\mathrm{sp}^{2}$ carbon [11].

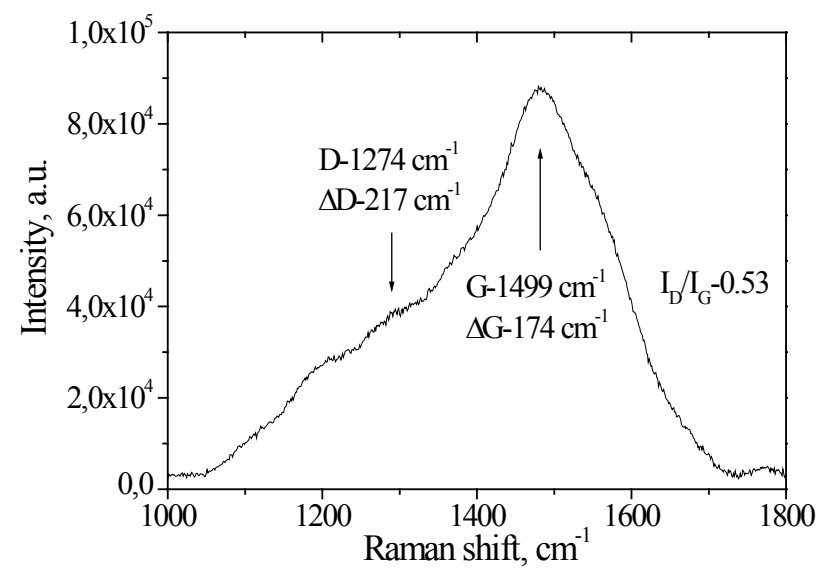

Fig. $1 \mu$ Raman spectrum of the DLC film.

The EDS results of the DLC film before and after laser irradiation are given in the Table 1. It should be noted that the EDS was measured in the depth exceeding the film thickness. The $d$ parameter indicates the distance (radius)

Table 1 Elemental compositions of the DLC film/substrate before and after laser irradiation by $1064 \mathrm{~nm}$

\begin{tabular}{ccccc}
\hline $\begin{array}{c}\text { Pulse } \\
\text { number }\end{array}$ & $\begin{array}{c}\text { Distance } \\
\text { from the spot } \\
\text { center, } \mu \mathrm{m}\end{array}$ & $\begin{array}{c}\mathrm{C}, \\
\text { at. } \%\end{array}$ & $\begin{array}{c}\text { O, } \\
\text { at. } \%\end{array}$ & $\begin{array}{c}\mathrm{Si}, \\
\text { at.\% }\end{array}$ \\
\hline DLC & - & 55.1 & 2.0 & 42.9 \\
1 & $\mathrm{~d} \leq 15$ & 21.8 & 4.1 & 74.1 \\
1 & $\mathrm{~d} \geq 15$ & 58.0 & 4.3 & 37.7 \\
10 & $\mathrm{~d}<10$ & 5.6 & 4.6 & 89.8 \\
10 & $15 \leq \mathrm{d} \leq 30$ & 49.9 & 5.6 & 44.5 \\
100 & $\mathrm{~d}<10$ & 2.9 & 1.1 & 96.0 \\
100 & $20 \leq \mathrm{d} \leq 40$ & 18.0 & 30.3 & 51.7 \\
100 & $\mathrm{~d}>40$ & 41.7 & 16.3 & 42.0 \\
\hline
\end{tabular}

from the laser spot center, where EDS measurements were performed.

The irradiation of DLC film by the first harmonic with a single pulse at $1.02 \mathrm{~J} / \mathrm{cm}^{2}$ partly removes the film from the Si substrate. The ablated spot diameter is about $30 \mu \mathrm{m}$ (Fig. 2a). Splats of DLC films still could be found at higher imagination on the surface. The carbon concentration decreased down to 21.8 at. $\%$, while oxygen increased twice (Table 1). Also such laser fluency influenced to the formation of the chaotically distributed ripples (Fig. 2a). The various size micro-fragments outside the ablated area are chaotically distributed. The elemental composition is similar to non-radiated film in radius zone of $15 \mu \mathrm{m} \leq \mathrm{d} \leq 30$ $\mu \mathrm{m}$ from the center. The melted Si substrate zone (with diameter of $\sim 30 \mu \mathrm{m}$ ) appeared with the increase of the number of pulses up to 10 . The melted silicon area is surrounded by the micro-ripple pattern zone (Fig. 2b). The carbon content decreased down to 5.6 at.\%, while the oxygen concentration increased up to 4.6 at. $\%$ in the melted zone.
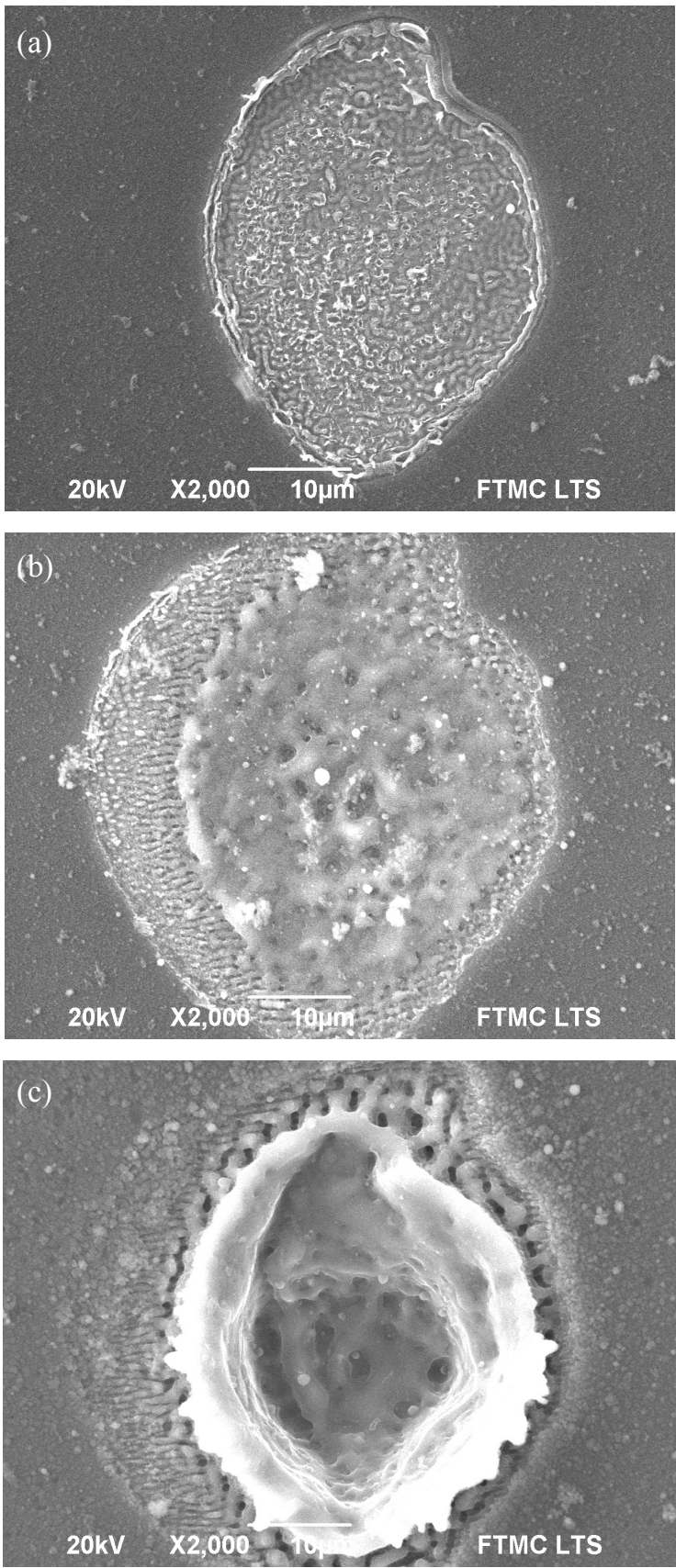

Fig. 2 Surface morphology of DLC films irradiated by the first harmonic with $1.02 \mathrm{~J} / \mathrm{cm}^{2}$ at different laser pulses

$$
\text { a) } 1 \text {, b) } 10 \text {, and c) } 100 \text {. }
$$

The hole of $10 \mu \mathrm{m}$ depth and $\sim 20 \mu \mathrm{m}$ diameter was observed after irradiation with 100 pulses. EDS results indicated very low amount of carbon (2.9 at.\%) and oxygen (1.1 at.\%). However similar to 10 pulses per spot, the narrow ripple zone around the hole also was formed (Fig. 2c). EDS measurements showed only 18 at.\% of carbon and high concentration (30.3 at.\%) of oxygen in the radius area $20 \mu \mathrm{m} \leq \mathrm{d} \leq 40 \mu \mathrm{m}$ from the center. It should be noted that even at $\mathrm{d}>40 \mu \mathrm{m}$ away from the spot center the oxygen 
fraction was higher compared to the non-affected DLC film (Table 1)

The $\mu$ Raman spectrum measured from the spot center irradiated by 100 laser pulses indicates the low intensity D $\left(1335 \mathrm{~cm}^{-1}\right)$ and $\mathrm{G}\left(1591 \mathrm{~cm}^{-1}\right)$ peaks, and intense broad band at $\sim 960 \mathrm{~cm}^{-1}$ (Fig. $3 \mathrm{~b}$ ). The broad band can be deconvoluted into several Gaussian peaks. The peak around $960 \mathrm{~cm}^{-1}$ is attributed to the $\mathrm{Si}$ (2nd order) and the peak around $980-1020 \mathrm{~cm}^{-1}$ corresponds to the stretching mode of $\mathrm{Si}-\mathrm{O}-\mathrm{Si}$ configuration in which $\mathrm{Si}$ atoms were in turn back bonded to the oxygen atoms [20-21]. The EDS and RS measurements confirmed that DLC film was removed in the laser spot center. Existence of low intensity D and $G$ peaks can be conditioned feet back DLC fragments after films spallation. Moreover, it is also probably that the low amount of carbon is dissolved into $\mathrm{Si}$ substrate. The $\mathrm{D}$ $\left(1338 \mathrm{~cm}^{-1}\right)$ and $\mathrm{G}\left(1588 \mathrm{~cm}^{-1}\right)$ peaks became separated in the $\mu \mathrm{RS}$ spectrum measured at the $20 \mu \mathrm{m} \leq \mathrm{d} \leq 40 \mu \mathrm{m}$ zone (Fig. 3a). The $\Delta \mathrm{D}$ peak narrowed to $127 \mathrm{~cm}^{-1}$, while $\Delta \mathrm{G}$ narrowed to $101 \mathrm{~cm}^{-1}$. As a result of this, $\mathrm{I}_{\mathrm{D}} / \mathrm{I}_{\mathrm{G}}$ ratio increased up to 1.27 . The increase of the $\mathrm{I}_{\mathrm{D}} / \mathrm{I}_{\mathrm{G}}$ ratio represents a reduction of the amount of $\mathrm{sp}^{3} \mathrm{C}-\mathrm{C}$ sites and an increase of the amount of the graphite structure [11]. The appearance of the low intensity peaks at $\sim 1120 \mathrm{~cm}^{-1}$ and $\sim 1480 \mathrm{~cm}^{-1}$ are assigned to trans-polyacetylene segments at grain boundaries $[20,22]$. These results indicate that the modified film is composed from a mixture of $\mathrm{sp}^{3} / \mathrm{sp}^{2}$ sites with dominant $\mathrm{sp}^{2} \mathrm{C}=\mathrm{C}$ sites and formation of the nanocrystalline graphite or glass carbon phase.
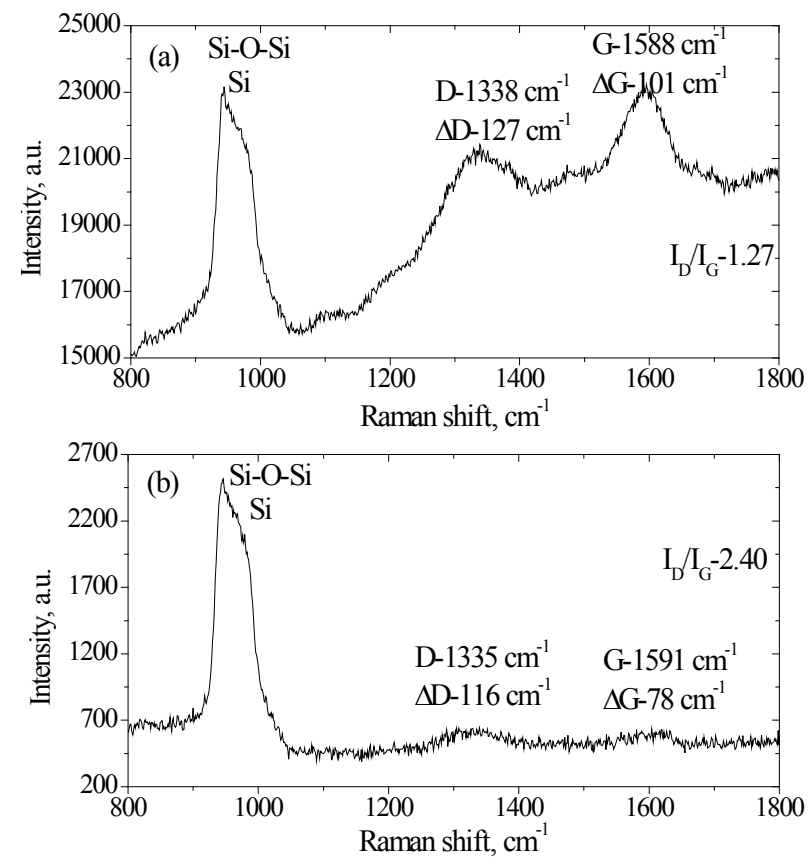

Fig. $3 \mu$ Raman spectra of the DLC film irradiated by the $1064 \mathrm{~nm}$ laser beam by 100 pulses (a) near ablated zone,

(b) spot center.

The irradiation by the first harmonic demonstrated the increase of the ablation area with the increase of the pulse numbers. The radius of ablation zone was smaller than the radius of the laser beam spot measured at $1 / \mathrm{e}^{2}$ level. The DLC film fully ablation occurs only in the $15-20 \mu \mathrm{m}$ radius area depending on the pulse number.
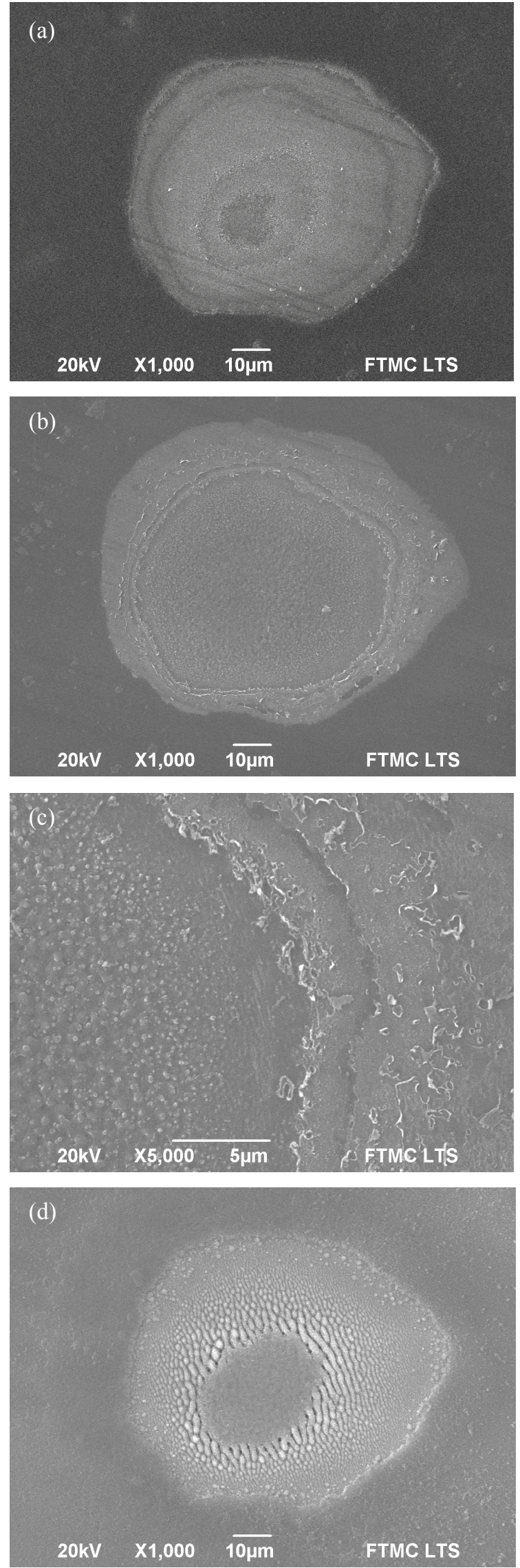

Fig. 4 Surface morphology of DLC films irradiated with $355 \mathrm{~nm}$ at various laser pulses a) 1, b) and c) 10, d) 100 .

The explanation of obtained results is related with band gap of the irradiated DLC film and Si substrate. The photon 
energy $(1.165 \mathrm{eV})$ of the laser beam is below the energy band gap of DLC $(1.5-2 \mathrm{eV})$ film, for the case of the 1064 $\mathrm{nm}$ wavelength, but it is above the band gap of $\mathrm{Si}(1.11 \mathrm{eV})$. Thereby the laser photons can pass through DLC film and then be absorbed by silicon substrate inducing local annealing. The increase of the pulse number rises the temperature in the irradiated zone, which induces melting of the Si and formation of pinholes in the substrate as well.

The irradiation of the DLC film with a single pulse at $0.79 \mathrm{~J} / \mathrm{cm}^{2}$ induced the uneven ablation and slight stratification of the film (Fig. 4a). The DLC film was ablated and Si substrate was local melted in the area of $\sim 60 \mu \mathrm{m}$ diameter when irradiation by 10 pulses per spot was used (Fig. $4 b)$. The ablated zone is surrounded by the terrace-like relief (Fig. 4c). The appearance of such structure demonstrates the multilayer delamination.

Different morphology depending on the position in the laser spot is observed at the surface after 100 pulses (Fig. $4 d)$. In the radius of the laser spot $d \leq 15 \mu \mathrm{m}$, the energy fluence was high to ablate the DLC film and to melt and ablate the silicon substrate. The DLC layer was ablated and the formation of non-regular ripples around the melted $\mathrm{Si}$ was observed $(15 \mu \mathrm{m} \leq \mathrm{d} \leq 30 \mu \mathrm{m})$. The DLC film was ablated and micro size fragments on the surface were distributed at position $30 \mu \mathrm{m} \leq \mathrm{d} \leq 40 \mu \mathrm{m}$ (Fig. 4d). The $\mu$ Raman spectrum of the melted and ripples formation areas showed a broad peak $\left(\sim 960 \mathrm{~cm}^{-1}\right)$ indicating amorphous/nanocrystalline $\mathrm{Si}$ and $\mathrm{Si}-\mathrm{O}-\mathrm{Si}$ sites [20]. Also a broad low intensity peak at $\sim 820 \mathrm{~cm}^{-1}$ was observed (Fig. 5). The peak at $820 \mathrm{~cm}^{-1}$ is attributed to the silicon carbide (SiC) $[6,23]$. The $\mu$ Raman spectrum does not demonstrate any $D$ and $G$ peaks, indicating that the film is completely ablated.

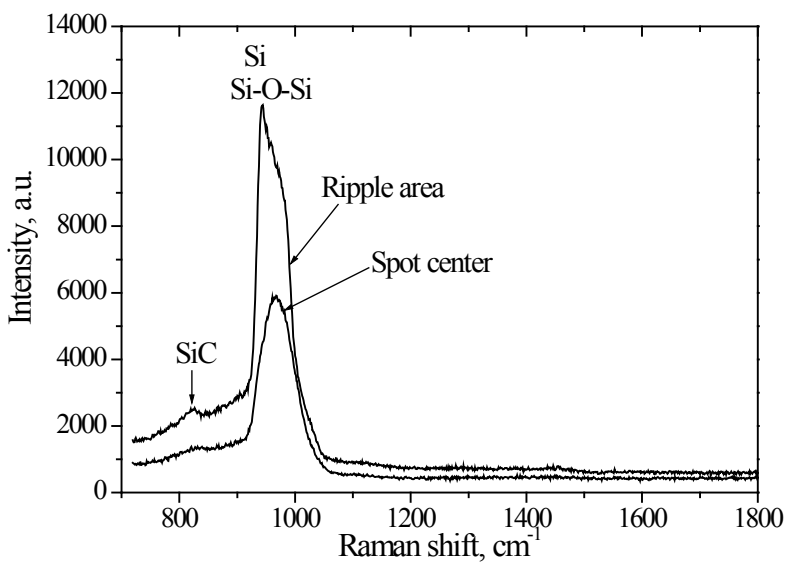

Fig. $5 \mu$ Raman spectra of the DLC film irradiated with the $355 \mathrm{~nm}$ laser beam by 100 pulses.

The DLC film was modified at the distance higher than $\mathrm{d} \geq 40 \mu \mathrm{m}$. The spectrum of modified carbon film is composed from the superposition of separated D $\left(1349 \mathrm{~cm}^{-1}\right)$ and $\mathrm{G}\left(1576 \mathrm{~cm}^{-1}\right.$ ) peaks (Fig. 6). The appearance of the peak at $1473 \mathrm{~cm}^{-1}$ is related to the trans-polyacetylene segments [20]. However, this peak can be related to the $A_{1}$. mode for five membered rings [24]. The position of D and $\mathrm{G}$ bands shifted to higher wave numbers, and both peaks narrowed, compared to non-radiated DLC film (Fig. 6). The $\mathrm{I}_{\mathrm{D}} / \mathrm{I}_{\mathrm{G}}$ ratio increased from 0.53 up to 1.31 . The rise of the $\mathrm{D}$ band and peaks splitting are the indication of the graphitization of the DLC film [18].

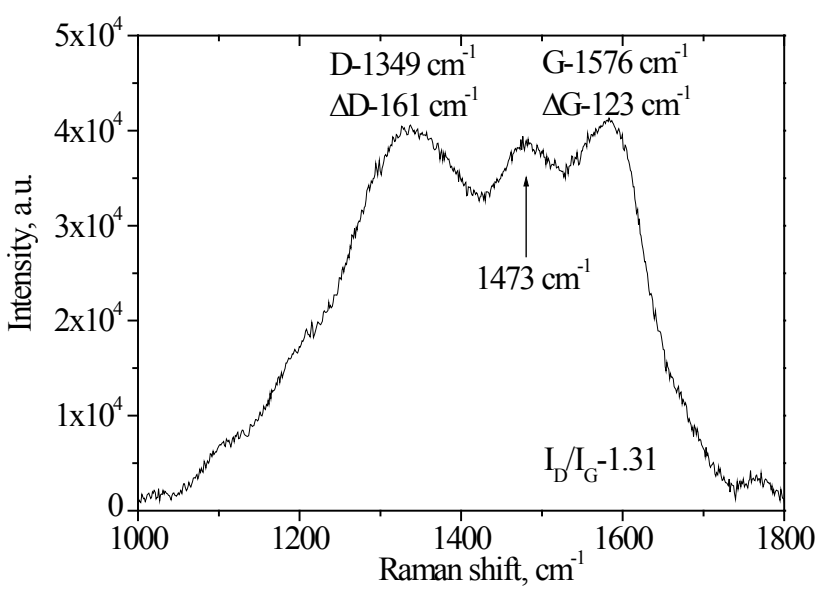

Fig. $6 \mu$ Raman spectrum of the DLC film after irradiation with the $355 \mathrm{~nm}$ laser beam by 100 pulses at $\mathrm{d}>40 \mu \mathrm{m}$ distance.

The irradiation of the $355 \mathrm{~nm}$ laser beam resulted in the fully DLC ablated zone radius twice larger than the laser spot radius at $1 / \mathrm{e}^{2}$ level. The dimension of the ablated DLC zones increases with the increase of the number of the pulses. The increase of the ablation zone related to the laser beam wavelength. The photon energy of the $355 \mathrm{~nm}$ laser beam is $\sim 3.5 \mathrm{eV}$. Thus the photon energy is higher than the energy band gap of DLC film and Si substrate as well as above the spectral energy of the $\pi-\pi^{*}$ interband transition. It will results the strong optical absorption in the volume of the carbon film and laser annealing of the DLC film. The annealing of the a-C:H film by the $266 \mathrm{~nm}$ laser beam was obtained by N.T. Panagiotopoulas et al. [6].

The laser photon energy is absorbed by the film, not reaching the silicon substrate when one pulse is used. The delamination of the film after one pulse reflects the spatial distribution of Gaussian beam intensity. The fluency of $0.79 \mathrm{~J} / \mathrm{cm}^{2}$ was enough to reach the melting temperature and start the evaporation of the DLC in the center of laser spot. The Gaussian energy distribution of the laser beam resulted non-homogeneous heating and temperature distribution in the film. The ablated area is increasing with the number of laser pulses due to accumulation of the energy. The irradiated DLC film is graphitized, the swelled surface is removed and finally the energy is transformed to the $\mathrm{Si}$ substrate resulting to the melting and partly ablation (Fig. 4d). G. Miyaji et al. [16] obtained changes in the bonding structure from DLC to graphite carbon certainly proceeds the ablation to form the nanostructures. T. Roch [14] found that at low fluences $\left(<500 \mathrm{~mJ} / \mathrm{cm}^{2}\right)$ the ablation rate is low and the surface swelling (graphitization) is dominating compared to the film ablation. However in our case, the fluence of $0.79 \mathrm{~J} / \mathrm{cm}^{2}$ was high enough to induce the graphitization of the film and when partly ablate the film even after one pulse.

\section{Conclusions}

The radius of ablated zone was smaller than the radius of the laser beam spot measured at $1 / \mathrm{e}^{2}$ level when the first 
harmonic (1064 nm) was used. The DLC film was removed from the laser spot center $(\mathrm{d}<15 \mu \mathrm{m})$ after irradiation with $1064 \mathrm{~nm}$ by 10 pulses and $1.02 \mathrm{~J} / \mathrm{cm}^{2}$ fluence. The irradiation of the $355 \mathrm{~nm}$ laser beam by 10 and 100 pulses per spot resulted in the fully DLC ablated zone radius twice larger than the laser spot radius. The irradiation with the third harmonic resulted to the delamination of the DLC. The picosecond laser irradiation stipulated graphitization of the DLC film near the ablated areas. The degradation of the Si substrate was minimized, and the area of the DLC film ablation was enlarged by the decrease of the laser wavelength. The investigations demonstrated that the ablation of the DLC proceeded due to the annealing of the Si substrate when the $1064 \mathrm{~nm}$ wavelength was used. Meanwhile, the irradiation with the third harmonic directly ablated the DLC film.

\section{Acknowledgments}

This article was prepared under support of the European Social Fund Agency implementing measure VP1-3.1-MM08-K of the Human Resources Development Operational Programme of Lithuania 2007-2013 3rd priority „Strengthening of capacities of researchers and scientists“ (project No. VP1-3.1-MM-08-K-01-013).

\section{References}

[1] E.G. Gamaly: Physics Reports, 508, (2011) 91.

[2] L. Li, M. Hong, M. Schmidt, M. Zhong, A. Malshe, B. Huis in'tVeld, and V. Kovalenko:, CIRP Ann. Manuf. Technol., 60, (2011) 735.

[3] F. Weng, C. Chen, and H. Yu: Mater. Design, 58, (2014) 412.

[4] R. Buividas, M. Mikutis, and S. Juodkazis: Prog. Quant. Electron., 38, (2014) 119.

[5] H. Fredriksson, D. Chakarov, and B. Kasemo: Carbon, 47, (2009) 1335.

[6] N.T. Panagiotopoulos, G. Karras, E. Lidorikis, D.C. Koutsogeorgis, C. Kosmidis, and P. Patsalas: Surf. Coat. Technol., 206, (2011) 734.
[7] G. Miyaji, and K. Miyazaki: J. Laser Micro/Nanoen., 3, (2008) 84.

[8] Q. Ding, L. Wang, L. Hu, T. Hu, and Y. Wang: Wear, 274-275, (2012) 43.

[9] T. Roch, E. Beyer, and A. Lasagni: Diamond Relat. Mater., 19, (2010) 1472.

[10] G.A. Cirino, R.D. Mansano, P. Verdonck, R.G. Jasinevičius, and L.G. Neto: Surf. Coat. Technol., 204, (2010) 2966.

[11] J. Robertson: J. Mater. Sci. Eng., R37, (2002) 129.

[12]P. Patsalas: Thin Solid Films, 519, (2011) 3990.

[13] Y. Dong, H. Sakata, and P. Molian: Appl. Surf. Sci., 252, (2005) 352.

[14] T. Roch, V.Weihnacht, H.J. Scheibe, A. Roch, and A. Lasagni: Diamond Relat. Mater., 33, (2013) 20.

[15] T.V. Kononenko et al. Diamond Relat. Mater., 14, (2005) 1368

[16] G. Miyaji, W. Kobayashi, and K. Miyazaki: J. Laser Micro/Nanoen., 2, (2007) 146.

[17] L. Marcinauskas, A. Grigonis, V. Vinciūnaite, and G. Račiukaitis: Cent. Eur. J. Phys., 9, (2011) 1344.

[18] L. Marcinauskas, A. Grigonis, P. Valatkevičius, and A. Medvids: Appl. Surf. Sci., 261, (2012) 488.

[19]Q. Ding, L.Wang, L. Hu, T. Hu, Y. Wang, and Y. Zhang: J. Appl. Phys. 109 (2011) 0135011.

[20] M. Veres, M. Koos, N. Orsos, S. Toth, M. Fule, M. Mohai, and I. Bertoti: Diamond Relat. Mater., 15, (2006) 932.

[21] V. Mankad, N.N. Ovsyuk, S.K. Gupta, and P. K. Jha: Physica B, 432, (2014) 116.

[22] A. Singha, A. Ghosh, A. Roy, and N.R. Ray: J. Appl. Phys., 100, (2006) 0449100.

[23] A. Dasgupta, S. Klein, L. Houben, R. Carius, F. Finger, and M. Luysberg: Thin Solid Films 516, (2008) 618.

[24] T.E. Doyle, and J.R. Dennison: Phys. Rev. B, 51, (1995) 196.

(Received: June 17, 2014, Accepted: December 13, 2014) 